\title{
Prognostic Analysis and Clinical Characteristics of Dual Primary Lung Cancer: A Population Study Based on Surveillance, Epidemiology, and End Results (SEER) Database
}

\section{Guanghui Wang \\ Shandong University \\ Yukai Zeng \\ Shandong University \\ Haotian Zheng \\ Shandong University \\ Xiaogang Zhao \\ Shandong University \\ Yadong Wang \\ Shandong University \\ Hongchang Shen \\ Shandong University}

Jiajun Du ( $\nabla$ dujiajun@sdu.edu.cn )

Shandong University https://orcid.org/0000-0003-2406-9435

\section{Research Article}

Keywords: dual primary lung cancer (DPLC), Prognostic Analysis, Clinical Characteristics, Surveillance, Epidemiology, End Results (SEER) database

Posted Date: July 16th, 2021

DOI: https://doi.org/10.21203/rs.3.rs-705632/v1

License: (c) (1) This work is licensed under a Creative Commons Attribution 4.0 International License. Read Full License

Version of Record: A version of this preprint was published at General Thoracic and Cardiovascular Surgery on March 22nd, 2022. See the published version at https://doi.org/10.1007/s11748-022-01795-6. 


\section{Abstract}

Background: The peculiarity and the lack of clinical studies of dual primary lung cancer (DPLC) led to limited knowledge about its clinical characteristics and prognosis. The current study performed a retrospective analysis and established a prognostic nomogram to assess the prognostic factors and clinical characteristics of DPLC.

Methods: A total of 1419 DPLC patients with pathological confirmation from SEER were selected and analyzed by univariate and multivariable Cox regression analyses. The independent prognostic factors were included to establish a nomogram. The accuracy and reliability of prognostic model were evaluated by $\mathrm{C}$-indexes, calibration plots, receiver operating characteristic (ROC) curves, decision curve analyses (DCA) and integrated discrimination improvement (IDI) scores. Chi-square test was used to assess the differences between DPLC and single primary lung cancer (SPLC) or synchronous DPLC (SDPLC) and metachronous DPLC (mDPLC).

Results: Cox regression analysis showed that age, sex, histological type, stage, LN metastasis, surgery, chemotherapy were independent prognostic factors, we included these factors to establish a prognostic model. In the training cohort, the C-index was 0.690 , and the area under curves (AUC) of 3- and 5-year survival time were 0.720 and 0.723 . The calibration plots in training cohort and validation cohort were in excellent agreement. DCA and IDI showed that the predictive effect of the novel prognostic model was better than the model based on 8th AJCC TNM system. Chi-square test indicated that DPLC and SPLC had statistical differences on pathological and clinical features.

Conclusions: The clinical and pathological characteristics of DPLC were different from the SPLC. The nomogram based on significant factors could provide accurate and individualized survival predictions for DPLC.

\section{Introduction}

Lung cancer has the high incidence and mortality, and is a leading cause of cancer death worldwide [1]. The incidence of dual primary lung cancer (DPLC) has also increased due to the improvement of medical level and the extension of survival time of lung cancer patients [2]. DPLC occupies the majority of multiple primary lung cancer (MPLC). And there are two subtypes of DPLC including synchronous DPLC (occurring at the same time) and metachronous DPLC (occurring at different times) [5, 6]. The incidence of DPLC is approximately $0.8 \%-14.5 \%$ per year for per non-small cell lung cancer patient who accesses to treatment $[3,4]$. Nevertheless, little studies pay attention to DPLC, clinicians still don't have a clear idea of the clinical features and prognosis about DPLC. Although the TNM stage system is used to evaluate prognosis widely, this criterion is more applicable to single primary lung cancer (SPLC). There are some limitations and disadvantages using TNM stage system to assess DPLC, because DPLC has different clinical features and pathological characteristics from single primary lung cancer. 
It is necessary to study the differences between SPLC and DPLC, and a dedicated clinical prognostic model for DPLC is urgently needed. The nomogram is a good choice for this purpose which evaluates the prognosis of DPLC patients owing to its convenience and accuracy [8-9]. Given the resulting paucity of data on prognosis and optimal management of DPLC, the aim of this study was to establish an accurate and reliable prognostic model which could predict the overall survival (OS) of DPLC patients and explore their clinical features. We performed a retrospective analysis based on the complete clinical information of DPLC and SPLC from the Surveillance, Epidemiology, and End Results (SEER) database and Provincial Hospital Affiliated to Shandong University. Verified nomogram which has compared with TNM stage system was used to predict the OS and Chi-square test was performed to research the clinical features of DPLC.

\section{Patients And Methods}

Data source. The relevant clinical information of DPLC and SPLC was extracted from SEER database between 2004 to 2015 by using SEER*Stat program version 8.3 .5 (http://seer.cancer.gov/seerstat/). In addition, MPLC patients' information was collected and selected from Provincial Hospital Affiliated to Shandong University.

Patient and variable selection. The following criteria were performed to select the DPLC patients in this study: 1. year of diagnosis was between 2004 to 2015; 2. site and morphology (site recoded ICD-O3/WHO 2008) were lung and bronchus; 3 . site and morphology (behavior recode for analysis) were malignant; 4. the lung cancers of patients were primary; 5 . the patients were defined as DPLC which their IDs were registered two times and the patients were defined ad SPLC which their IDs were registered once. Patients with one primary lung cancer or two primary lung cancer were included for this study, and the information of status, survival time, AJCC stage, and AJCC N and grade was clear. A total of 1419 DPLC patients and 70198 SPLC patients with pathological confirmation were selected from SEER database and 173 MPLC patients and 173 SPLC patients were selected from Provincial Hospital Affiliated to Shandong University. The variables included age at diagnosis, sex, race record, primary site label, laterality, grade, ICO-0-3 Hist/behav, malignancy, the time interval (months since the first tumor to the second tumor of the DPLC), AJCC TNM system, COD to site recode, Rx Summ-Surg Prim Site (1998+), radiation record, chemotherapy record, smoke, chronic disease, familial-hereditary disease and pre-cancer symptoms. We selected the grade with poorer differentiation and the later stage of the first primary lung cancer and second primary lung cancer as the final grade and stage of the patient. The patients' stage information recorded by 6th AJCC system was modified into 8th AJCC system.

\section{Statistical Analysis}

All statistical analyses were performed by SPSS (version 24.0; SPSS Inc., Chicago, IL) and R software (4.0.5). Survival time was counted from date of diagnosis (the second tumor of DPLC) to date of death. Simple random sampling was performed by SPSS. The univariate analysis and the COX multivariate analysis were used to explored the independent prognostic factors of SPLC and DPLC. OS analysis was 
performed by Kaplan - Meier method. The propensity score matching (PSM) was used to eliminate the differences between SPLC and DPLC or SDPLC and mDPLC. We used the chi-square test to examine the variables. X-tile software was used to calculate cut-off value of age. Results were reported by the hazard ratio and $95 \%$ confidence interval. All $p$ values were two-sided, and $p$ values less than 0.05 were considered statistically significant.

\section{Results}

\section{Univariate analysis and COX multivariate analysis for overall survival.}

According to the univariate analysis of 1419 DPLC patients, the results showed age, race, sex, histological type, grade, stage, LN (lymph nodes) metastasis, surgery, chemotherapy were associated with the overall survival of DPLC patients. After univariate analysis, Cox multivariate analysis were performed to examine the effect of each clinical variables on OS, and the analysis clarified that age, sex, histological type, stage, LN metastasis, surgery, chemotherapy were significant prognostic factors (log-rank test, all $p$ value $<0.05$; Table 1). Aged $\geq 72$ (HR 1.531; $95 \% \mathrm{Cl}: 1.271 \mathrm{t}-1.844 ; \mathrm{p}<0.001$ ) years old were associated with worse OS. The female patients were associated with better prognosis (HR 0.654; $95 \% \mathrm{Cl}$ : 0.566-0.755; $p<$ 0.001). The prognosis of patients with lung squamous cell carcinomas (either the first tumor or the second tumor) was associated with worse OS compared with lung adenocarcinoma patients. The following factors led to short OS: Stage $\otimes$ patients (HR 1.422; $95 \% \mathrm{Cl}: 1.120-1.805 ; p=0.004$ ) and Stage $\triangle$ patients (HR 1.961; 95 \% Cl: 1.563-2.460; $\mathrm{p}<0.001$ ), LN metastasis (HR 1.540; 95 \% Cl: 1.254-21.891; $\mathrm{p}<0.001$ ), surgery (Yes - No, HR 1.375; $95 \% \mathrm{Cl}$ : 1.146-1.649; $\mathrm{p}=0.001$ ) and surgery (No - No, HR 1.546; $95 \%$ Cl: $1.236-1.934 ; p<0.001)$. In order to more vividly reflect the relationship between independent prognostic factors and OS, Kaplan - Meier method curves were used to show the survival time of different factors (Fig. 1). 
Table 1

Univariate analysis and multivariate COX analysis of DPLC.

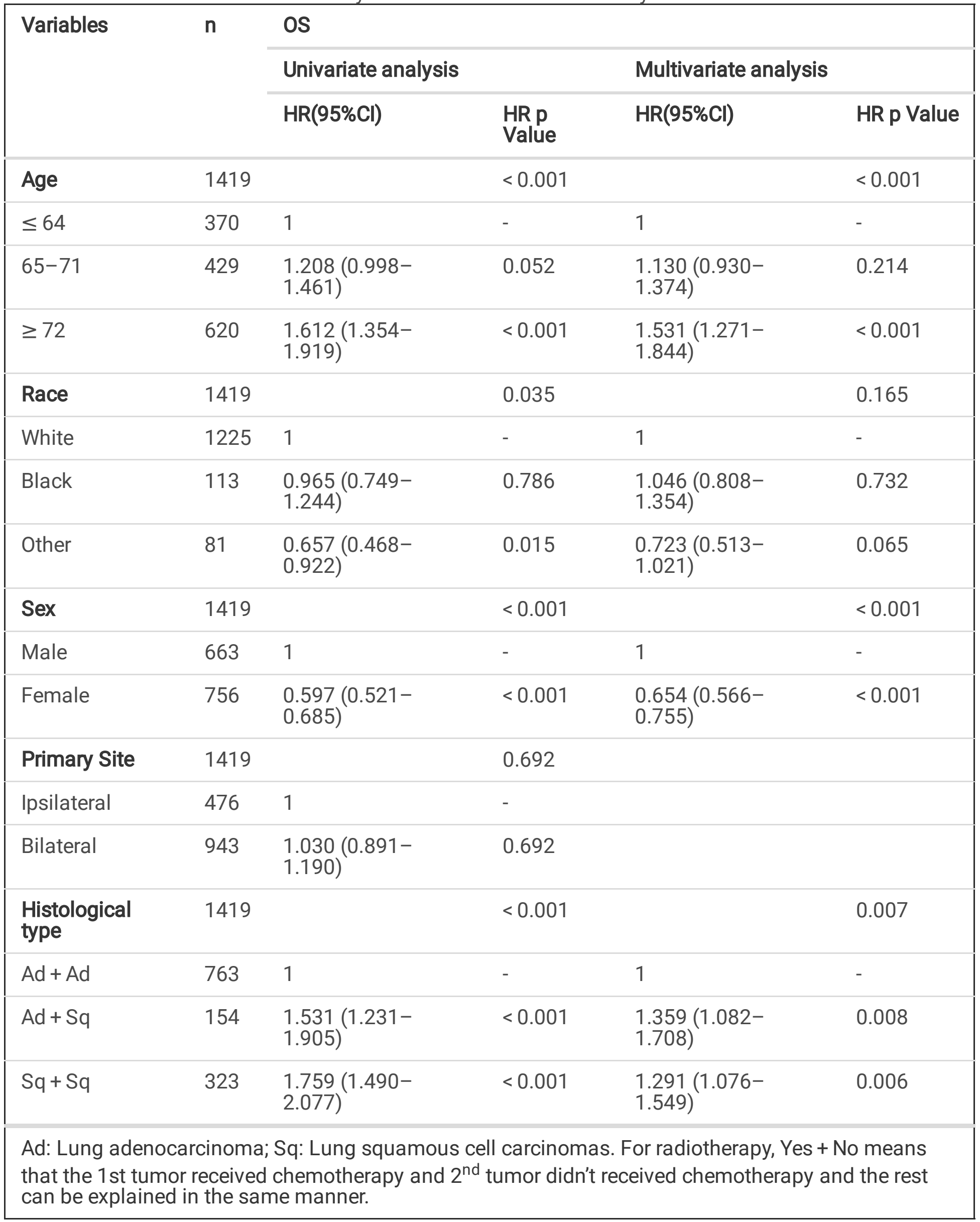




\begin{tabular}{|c|c|c|c|c|c|}
\hline \multirow[t]{3}{*}{ Variables } & \multirow[t]{3}{*}{$\mathbf{n}$} & \multicolumn{4}{|l|}{ OS } \\
\hline & & \multicolumn{2}{|l|}{ Univariate analysis } & \multicolumn{2}{|c|}{ Multivariate analysis } \\
\hline & & $\mathrm{HR}(95 \% \mathrm{Cl})$ & $\begin{array}{l}\text { HR p } \\
\text { Value }\end{array}$ & $\mathrm{HR}(95 \% \mathrm{Cl})$ & HR p Value \\
\hline $\mathrm{Sq}+\mathrm{Ad}$ & 179 & $\begin{array}{l}1.381(1.123- \\
1.699)\end{array}$ & 0.002 & $\begin{array}{l}1.284(1.033- \\
1.596)\end{array}$ & 0.024 \\
\hline Grade & 1419 & & $<0.001$ & & 0.077 \\
\hline Grade I & 110 & 1 & - & 1 & - \\
\hline Grade II & 588 & $\begin{array}{l}1.846(1.330- \\
2.561)\end{array}$ & $<0.001$ & $\begin{array}{l}1.544(1.102- \\
2.165)\end{array}$ & 0.012 \\
\hline Grade III & 699 & $\begin{array}{l}2.156(1.559- \\
2.982)\end{array}$ & $<0.001$ & $\begin{array}{l}1.566(1.114- \\
2.203)\end{array}$ & 0.01 \\
\hline Grade IV & 22 & $\begin{array}{l}2.210(1.221- \\
4.002)\end{array}$ & 0.009 & $\begin{array}{l}1.528(0.821- \\
2.845)\end{array}$ & 0.181 \\
\hline Stage & 1419 & & $<0.001$ & & $<0.001$ \\
\hline 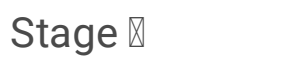 & 686 & 1 & - & 1 & - \\
\hline Stage $\otimes$ & 228 & $\begin{array}{l}1.270(1.034- \\
1.560)\end{array}$ & 0.023 & $\begin{array}{l}0.988(0.766- \\
1.274)\end{array}$ & 0.926 \\
\hline 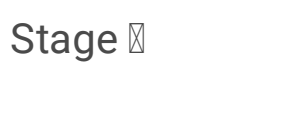 & 310 & $\begin{array}{l}1.917(1.614- \\
2.277)\end{array}$ & $<0.001$ & $\begin{array}{l}1.422(1.120- \\
1.805)\end{array}$ & 0.004 \\
\hline 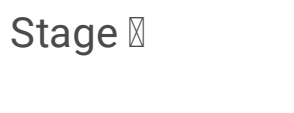 & 195 & $\begin{array}{l}2.588(2.127- \\
3.147)\end{array}$ & $<0.001$ & $\begin{array}{l}1.961(1.563- \\
2.460)\end{array}$ & $<0.001$ \\
\hline LN metastasis & 1419 & & $<0.001$ & & $<0.001$ \\
\hline No & 950 & 1 & - & 1 & - \\
\hline Yes & 469 & $\begin{array}{l}1.864(1.620- \\
2.144)\end{array}$ & $<0.001$ & $\begin{array}{l}1.540(1.254- \\
1.891)\end{array}$ & $<0.001$ \\
\hline Radiotherapy & 1419 & & 0.53 & & \\
\hline $\mathrm{No}+\mathrm{No}$ & 893 & 1 & - & & \\
\hline Yes + Yes & 116 & $\begin{array}{l}1.177(0.917- \\
1.511)\end{array}$ & 0.199 & & \\
\hline Yes + No & 169 & $\begin{array}{l}0.940(0.755- \\
1.171)\end{array}$ & 0.58 & & \\
\hline
\end{tabular}

Ad: Lung adenocarcinoma; Sq: Lung squamous cell carcinomas. For radiotherapy, Yes + No means that the 1 st tumor received chemotherapy and $2^{\text {nd }}$ tumor didn't received chemotherapy and the rest can be explained in the same manner. 


\begin{tabular}{|c|c|c|c|c|c|}
\hline \multirow[t]{3}{*}{ Variables } & \multirow[t]{3}{*}{$\mathrm{n}$} & \multicolumn{4}{|l|}{ OS } \\
\hline & & \multicolumn{2}{|c|}{ Univariate analysis } & \multicolumn{2}{|c|}{ Multivariate analysis } \\
\hline & & $\mathrm{HR}(95 \% \mathrm{Cl})$ & $\begin{array}{l}\text { HR p } \\
\text { Value }\end{array}$ & $\mathrm{HR}(95 \% \mathrm{Cl})$ & HR p Value \\
\hline $\mathrm{No}+$ Yes & 241 & $\begin{array}{l}1.023(0.848- \\
1.235)\end{array}$ & 0.809 & & \\
\hline Surgery & 1419 & & $<0.001$ & & $<0.001$ \\
\hline Yes + Yes & 900 & 1 & - & 1 & - \\
\hline Yes + No & 317 & $\begin{array}{l}1.748(1.475- \\
2.071)\end{array}$ & $<0.001$ & $\begin{array}{l}1.375(1.146- \\
1.649)\end{array}$ & 0.001 \\
\hline $\mathrm{No}+\mathrm{Yes}$ & 25 & $\begin{array}{l}1.615(0.948- \\
2.751)\end{array}$ & 0.078 & $\begin{array}{l}1.447(0.830- \\
2.522)\end{array}$ & 0.192 \\
\hline $\mathrm{No}+\mathrm{No}$ & 177 & $\begin{array}{l}2.189(1.789- \\
2.678)\end{array}$ & $<0.001$ & $\begin{array}{l}1.546(1.236- \\
1.934)\end{array}$ & $<0.001$ \\
\hline Chemotherapy & 1419 & & $<0.001$ & & 0.007 \\
\hline $\mathrm{No}+\mathrm{No}$ & 833 & 1 & - & 1 & - \\
\hline Yes + Yes & 201 & $\begin{array}{l}1.635(1.356- \\
1.972)\end{array}$ & $<0.001$ & $\begin{array}{l}1.025(0.824- \\
1.275)\end{array}$ & 0.826 \\
\hline Yes + No & 219 & $\begin{array}{l}0.962(0.780- \\
1.187)\end{array}$ & 0.72 & $\begin{array}{l}0.751(0.598- \\
0.943)\end{array}$ & 0.014 \\
\hline $\mathrm{No}+\mathrm{Yes}$ & 166 & $\begin{array}{l}1.613(1.312- \\
1.985)\end{array}$ & $<0.001$ & $\begin{array}{l}1.214(0.967- \\
1.524)\end{array}$ & 0.095 \\
\hline Interval & 1419 & & 0.163 & & \\
\hline$<6$ months & 549 & 1 & - & & \\
\hline$\geq 6$ months & 870 & $\begin{array}{l}1.104(0.960- \\
1.270)\end{array}$ & 0.163 & & \\
\hline $\begin{array}{l}\text { Ad: Lung adeno } \\
\text { that the } 1 \text { st tum } \\
\text { can be explaine }\end{array}$ & $\begin{array}{l}\text { nom } \\
\text { ceive }\end{array}$ & $\begin{array}{l}\text { q: Lung squan } \\
\text { lemotherapy a } \\
\text { manner. }\end{array}$ & $\begin{array}{l}\text { arcinor } \\
\text { mor did }\end{array}$ & $\begin{array}{l}\text { or radiotherap } \\
\text { eived chemoth }\end{array}$ & $\begin{array}{l}\text { o means } \\
d \text { the rest }\end{array}$ \\
\hline
\end{tabular}

\section{Propensity score matching of SPLC and DPLC.}

In our study, the OS rates of DPLC and SPLC patients were compared by Kaplan - Meier method. Because of the confounding factors, the survival rates between the two groups showed incomprehensible results which the SPLC patients had poor prognosis than DPLC patients (Fig. $2 A, p<0.001$ ). 
We extracted the 900 DPLC patients with surgery and 900 SPLC patients with surgery which were extracted by the random sampling method from 70198 SPLC patients to perform PSM analysis. The factors of grade, LN metastasis and stage were included into the PSM analysis. The differences of factors between the two groups were eliminated by PSM (Table supplement 1). Kaplan - Meier method was used to explore the OS of matching data, and the result showed that the DPLC patients were associated with the poor prognosis (Fig. 2B).

\section{Clinical and pathological differences between DPLC and SPLC.}

The 1419 SPLC patients were extracted from 70198 SPLC patients by the random sampling method. The pathological differences among the single primary lung tumor, 1st tumor of DPLC and 2nd tumor of DPLC were examined by chi-square test (Table 2). According to Table 2, we could draw a conclusion that the

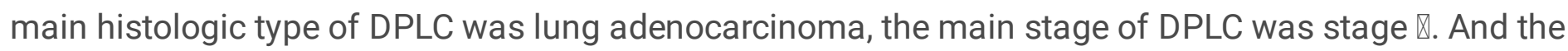
distant metastasis of PDLC was rare. 
Table 2

The analysis of pathological characteristics between SPLC patients and DPLC patients.

\begin{tabular}{|c|c|c|c|c|c|c|c|c|c|}
\hline Variables & primary & $1 s t$ & $p$ & $1 s t$ & 2nd & p & primary & 2nd & $p$ \\
\hline \multicolumn{10}{|l|}{ Laterality } \\
\hline Left & 576 & 637 & \multirow[t]{2}{*}{0.021} & 637 & 649 & \multirow[t]{2}{*}{0.639} & 576 & 649 & \multirow[t]{2}{*}{0.005} \\
\hline Right & 843 & 782 & & 782 & 769 & & 843 & 769 & \\
\hline \multicolumn{10}{|l|}{$\begin{array}{l}\text { Histologic } \\
\text { type }\end{array}$} \\
\hline $\mathrm{Ad}$ & 860 & 917 & \multirow[t]{2}{*}{0.027} & 917 & 942 & \multirow[t]{2}{*}{0.324} & 860 & 942 & \multirow[t]{2}{*}{0.001} \\
\hline $\mathrm{Sq}$ & 559 & 502 & & 502 & 477 & & 559 & 477 & \\
\hline \multicolumn{10}{|l|}{ Grade } \\
\hline$\square$ & 142 & 222 & \multirow{4}{*}{$\begin{array}{l}<.001 \\
0.00\end{array}$} & 222 & 313 & \multirow{4}{*}{$\dot{0} 001$} & 142 & 313 & \multirow{4}{*}{$\begin{array}{l}<.001 \\
0.00\end{array}$} \\
\hline ૫ & 547 & 669 & & 669 & 664 & & 547 & 664 & \\
\hline$\square$ & 718 & 512 & & 512 & 434 & & 718 & 434 & \\
\hline$\square$ & 12 & 16 & & 16 & 8 & & 12 & 8 & \\
\hline \multicolumn{10}{|l|}{$\mathrm{T}$} \\
\hline T1 & 862 & 1101 & \multirow{4}{*}{$\begin{array}{l}<.001 \\
0.00\end{array}$} & 1101 & 1184 & \multirow{4}{*}{$<.001$} & 862 & 1184 & \multirow{4}{*}{$\dot{0.001}$} \\
\hline T2 & 138 & 104 & & 104 & 49 & & 138 & 49 & \\
\hline T3 & 104 & 96 & & 96 & 113 & & 104 & 113 & \\
\hline T4 & 315 & 118 & & 118 & 73 & & 315 & 73 & \\
\hline \multicolumn{10}{|l|}{$\mathbf{N}$} \\
\hline NO & 732 & 950 & \multirow{2}{*}{$<.001$} & 950 & 950 & \multirow[t]{2}{*}{1} & 732 & 950 & \multirow{2}{*}{$\begin{array}{l}<.001 \\
0.001\end{array}$} \\
\hline N1-3 & 687 & 469 & & 469 & 469 & & 687 & 469 & \\
\hline \multicolumn{10}{|l|}{$M$} \\
\hline MO & 993 & 1339 & \multirow{2}{*}{$<.001$} & 1339 & 1271 & \multirow{2}{*}{$\begin{array}{l}< \\
0.001\end{array}$} & 993 & 1271 & \multirow{2}{*}{$<.001$} \\
\hline M1 & 426 & 80 & & 80 & 148 & & 426 & 148 & \\
\hline \multicolumn{10}{|l|}{ Stage } \\
\hline$\square$ & 487 & 944 & \multirow{3}{*}{$\begin{array}{l}<.001 \\
0.001\end{array}$} & 944 & 957 & \multirow{3}{*}{$\begin{array}{l}<.001 \\
0.001\end{array}$} & 487 & 957 & \multirow{3}{*}{$<$} \\
\hline$\square$ & 145 & 169 & & 169 & 159 & & 145 & 159 & \\
\hline$\square$ & 361 & 226 & & 226 & 155 & & 361 & 155 & \\
\hline
\end{tabular}




\begin{tabular}{|c|c|c|c|c|c|c|c|c|c|}
\hline Variables & primary & 1st & $p$ & 1st & 2nd & $p$ & primary & 2nd & $p$ \\
\hline प & 426 & 80 & & 80 & 148 & & 426 & 148 & \\
\hline
\end{tabular}

The clinical characteristics were analyzed by the patients' information from Provincial Hospital Affiliated to Shandong University. A total of 173 SPLC patients and 173 MPLC patients were included into chisquare test (Fig. 3). The proportion of male and female patients with DPLC was approximately the same, but the male SPLC patients made up the majority. Most MPLC patients didn't smoke and have chronic diseases before the occurrence of cancer.

There results also indicated that the pathogenesis and etiology might be different from MPLC and SPLC.

\section{Prognostic nomogram for DPLC.}

A total of 1419 patients from SEER database were randomly divided into the training cohort and validation cohort. The training cohort accounted for $70 \%$ of the total cases. To predict the survival time of DPLC patients, the patients' information of training cohort was used to establish a nomogram including aforementioned significant factors (Fig. 3). The prognostic nomogram showed that surgery contributed the most to the OS of DPLC, followed by age, sex, histological type, stage, LN metastasis. The 3- and 5year OS rates of the prediction results were shown in Fig. 3. The different classification of each factor was assigned a score on the point scale. The total score was calculated by adding all the scores of these factors. The higher score was associated with the worse survival prognosis. The nomogram could be used to predict each patient's survival time according to their own conditions.

\section{Validation of predictive model's accuracy.}

Accuracy of the nomogram was examined by the $\mathrm{C}$ - index, the ROC curve, the calibration chart. The Cindex of training cohort was 0.69 (95\% Cl: 0.678-0.702), and the C-index of validation cohort was 0.681 ( $95 \% \mathrm{Cl}: 0.663-0.699)$. Both of them had good predictive value. The 3 - and 5-year AUC values of the ROC curves were 0.720 and 0.723 on training cohort (Fig. 4A). The 3- and 5-year AUC values of the ROC curves were 0.696 and 0.755 on validation cohort (Figure supplement $1 \mathrm{~A}$ ). Additionally, the calibration plots presented an acceptable and excellent consistency between predicted results and actual observations for 3- and 5- year OS rates in training cohort and validation cohort (Fig. 4B and Figure supplement 1B). We could observe that all calibration curves were closed to ideal the $45^{\circ}$ dotted line.

To verify the predictive ability of the nomogram, the DCA was used to compare both the predictive model and the AJCC TNM system. The 3- and 5- year DCA curves of training cohort and validation cohort were shown on Fig. $4 \mathrm{C}$ and Figure supplement 1C. All the DCA curves presented that the new model had a more accurate prediction ability than the AJCC TNM system. The IDI values of 3- and 5-year were $7.8 \%$ $(p<0.001)$ and $9.2 \%(p<0.001)$ on training cohort, and the IDI values of 3 - and 5 -year were $5.1 \%(p<$ $0.001)$ and $7.4 \%(p<0.001)$ on validation cohort. The IDI results were in line with DCA curves. 


\section{Discussion}

In recent years, a large number of studies focused on SPLC, but there were few studies on DPLC. To date, little is known about the prognostic factors and clinical characteristics of DPLC. An accurate predictive model and well-defined clinical features of DPLC are urgently needed. This study retrospectively analyzed the DPLC patients extracted from SEER database between 2004-2015. Univariate Cox regression and multivariable Cox regression analysis were used to explore the significant clinical factors and these factors were used to establish a prognostic model. Apart from that, the comparison between DPLC and SPLC was analyzed according to the information from SEER database and Provincial Hospital Affiliated to Shandong University.

In this study, we found that age, sex, histological type, stage, LN metastasis, surgery, chemotherapy were significant factors which were associated with the prognosis of DPLC patients. These results were broadly consistent with other studies, but Cong-kuan Song et al found that race, grade also had an impact on prognosis of DPLC [10].

Surgical resection is a main therapeutic method which benefits the most DPLC patients to prolong their OS [11]. Our study also showed that the survival time of patients with two operations was longer than other patients without surgery. And previous studies showed that radiation and chemotherapy emerged as the effective alternative methods for patients for whom surgery was contraindicated or was not in-line with the patient's wishes $[12,13]$. However, we found that only chemotherapy could prolong survival time of DPLP, radiotherapy was not independent diagnostic factor for DPLC patients.

Astonishingly, the OS of SPLC was shorter than DPLC (Fig. 2A). We speculated that the clinical and pathological features between SPLC and DPLC were so different that the confounding factors confounded our judgment to survival time. The key prognostic factors such as grade, LN metastasis, stage were extracted to perform the PSM analysis, considering the interference of confounding factors. And the Kaplan - Meier curve showed reasonable outcome which the OS rate of DPLC was lower after PSM analysis (Fig. 2B).

Some previous study proposed a diagnostic criterion which DPLC could be divided into synchronous DPLC and metachronous DPLC according to interval time (6 months) of the 1 st and 2 nd tumor of DPLC [14]. Martini and Melamed thought the interval time of MMPLC was 2 years based on 50 cases in 1975[17]. But the American College of Chest Physicians put forward the diagnostic criteria that the interval time was 4 years in 2007 [16]. Our study adopted the point of view which the time was 6 months. But it was confused that the interval time wasn't significant prognostic factor, when it was included into Cox regression analysis. Considering the influence of confounding factors, we performed the PSM to eliminate the difference between SDPLC and MDPLC, however, there still remained some bias after PSM. And the Kaplan - Meier curve showed that there were not any differences between their OS rates after PSM ( $p>0.05)$. Cong-kuan Song et al also found the results [10]. There were two possible reasons for this, firstly, we acknowledged the statistical limitations of the study due to the small sample size, secondly, the diagnostic criteria of interval were unreasonable. There results inspired that the further 
research could pay an attention to define new interval time which has more prognostic significance according to more data.

The Chi-square analysis was used to examine the differences of SPLC and DPLC. We used the data from SEER database to analyze the pathological differences, and used the data from Provincial Hospital Affiliated to Shandong University to analyze the clinical differences (Table 2 and Table 3). 
Table 3

The analysis of clinical characteristics between SPLC patients and DPLC patients.

\begin{tabular}{|c|c|c|c|c|c|}
\hline \multirow[t]{2}{*}{ Variables } & \multicolumn{2}{|c|}{ SPLC } & \multicolumn{3}{|c|}{ MPLC } \\
\hline & $\mathbf{n}$ & $\%$ & $\mathbf{n}$ & $\%$ & \\
\hline \multicolumn{6}{|l|}{ Sex } \\
\hline Male & 130 & 75.14 & 88 & 50.87 & \multirow[t]{2}{*}{$<0.001$} \\
\hline Female & 43 & 24.86 & 85 & 49.13 & \\
\hline \multicolumn{6}{|l|}{ Age } \\
\hline$<60$ & 82 & 47.40 & 95 & 54.91 & \multirow[t]{2}{*}{0.162} \\
\hline$\geq 60$ & 91 & 52.60 & 78 & 45.09 & \\
\hline \multicolumn{6}{|l|}{ Smoke } \\
\hline Yes & 119 & 68.79 & 65 & 37.57 & \multirow[t]{2}{*}{$<0.001$} \\
\hline No & 54 & 31.21 & 108 & 62.43 & \\
\hline \multicolumn{6}{|c|}{ Chronic disease } \\
\hline Yes & 119 & 68.79 & 54 & 31.21 & \multirow[t]{2}{*}{$<0.001$} \\
\hline No & 54 & 31.21 & 119 & 68.79 & \\
\hline \multicolumn{6}{|c|}{ Familial-hereditary disease } \\
\hline Yes & 29 & 16.76 & 28 & 16.18 & \multirow[t]{2}{*}{0.885} \\
\hline No & 144 & 83.24 & 145 & 83.82 & \\
\hline \multicolumn{6}{|c|}{ Pre-cancer symptoms } \\
\hline Yes & 118 & 68.21 & 93 & 53.76 & \multirow[t]{2}{*}{0.006} \\
\hline No & 55 & 31.79 & 80 & 46.24 & \\
\hline \multicolumn{6}{|c|}{ LN Metastasis } \\
\hline Yes & 68 & 39.31 & 44 & 25.43 & \multirow[t]{2}{*}{0.006} \\
\hline No & 105 & 60.69 & 129 & 74.57 & \\
\hline
\end{tabular}

The pathological differences between the SPLC and DPLC were mainly reflected in laterality, histologic type, grade and TNM stage. The histologic type of DPLC mainly was adenocarcinoma, and this 


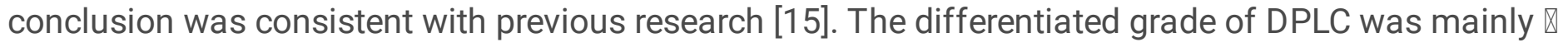

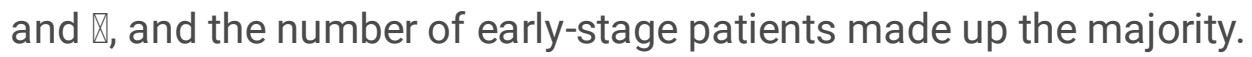

The clinical differences between the DPLC and SPLC mainly were sex, smoke, chronic disease, pre-cancer symptoms. In SPLC patient's cohort, the male patients accounted for $75.14 \%$, the female patients accounted for $24.86 \%$. And the 119 patients with smoking habit accounted $68.79 \%$. In DPLC patient's cohort, the proportion of sex was about the same, and the majority of patients hadn't the smoking habit. Most MPLC patients didn't have chronic diseases and pre-cancer symptoms, which brought difficulties to the timely diagnosis for patients' diseases.

It is noteworthy that there are still no specific treatment guidelines and plan for DPLC. The nomogram was widely used to predict the prognosis for cancer, primarily because of their ability to include statistical predictive factors into a multivariate visualization gram [7]. Considering the advantages of nomogram, we included aforementioned independent prognostic factors to establish a nomogram for predicting the OS of patients. The effectiveness was assessed by C-index, ROC curve and calibration plot, and the assessment results indicated that the nomogram had the excellent accuracy and predictability. Clinicians used the traditional 8th AJCC TNM system to access the progression of cancer, but the system couldn't predict the OS of patients and provide clinical guidance. And the assessment ability of the system lacked specificity for cancer subtypes. The nomogram made up for the shortcomings of the 8th AJCC TNM system, because we included clinical factors and therapy methods into the model. DCA curves were used to certify that the predictability of the new model was better than the 8th AJCC TNM system in training and validation cohort (Fig. 4 and Figure supplement 1). The IDI values also proved these results.

Our study has the following advantages. Firstly, this study established a nomogram to predict survival time of DPLC. This model could be used to improve prediction capabilities. Then, this study was the first attempt to performed the Chi-square analysis and PSM analysis for comparing the differences of DPLC and SPLC. This work expanded our knowledge of DPLC. Certainly, there are some shortcomings in our research. We did not clearly explore the differences between SDPLC and SDPLC because of the lack of data. And the patients' number from Provincial Hospital Affiliated to Shandong University was so insufficient that the clinical features couldn't be explored clearly. Considering the shortcomings of this study, further prospective analysis should be recommended.

\section{Declarations}

\section{Acknowledgements}

We thank all patients, investigators, and institutions involved in this study, especially the SEER database and Provincial Hospital Affiliated to Shandong University for providing platforms and valuable data sets.

\section{Funding}


This study was supported by the Jinan Science and Technology Plan (grant no. 202019058) and the Natural Science Foundation of Shandong Province (grant no. ZR2019MH026).

\section{Availability of data and materials}

The datasets used and analyzed during the current study are available from the corresponding author on reasonable request.

\section{Authors' contributions}

Jiajun Du, Guanghui Wang and Yukai Zeng designed the experiments. Xiaogang Zhao, Yadong Wang, Hongchang Shen, Haotian Zheng collected and processed the data. Yukai Zeng wrote and polished article. All of the authors read and approved the final manuscript. All authors contributed to data analysis, drafting or revising the article, have agreed on the journal to which the article will be submitted, gave final approval of the version to be published, and agree to be accountable for all aspects of the work.

\section{Ethics approval and consent to participate}

Not applicable.

\section{Consent for publication}

The authors agree to publish.

\section{Competing interests}

The authors declare that they have no competing interests.

\section{References}

1. Qu J, Wang L, Jiang M, Zhao D, Wang Y, Zhang F, Li J, Zhang X. A Review About Pembrolizumab in First-Line Treatment of Advanced NSCLC: Focus on KEYNOTE Studies. Cancer Manag Res 2020;12.

2. Wang H, Hou J, Zhang G, Zhang M, Li P, Yan X, Ma Z. Clinical characteristics and prognostic analysis of multiple primary malignant neoplasms in patients with lung cancer. Cancer Gene Ther 2019 11;26.

3. Rakesh Surapaneni, Priya Singh, Kumar Rajagopalan, Alexandre Hageboutros. Stage I lung cancer survivorship: risk of second malignancies and need for individualized care plan. J Thorac Oncol. 2012 Aug;7(8):1252-6.

4. Hamaji M, Allen MS, Cassivi SD, Deschamps C, Nichols FC, Wigle DA, Shen KR. Surgical treatment of metachronous second primary lung cancer after complete resection of non-small cell lung cancer. $J$ Thorac Cardiovasc Surg 2013 Mar;145(3).

5. Shintani Y, Okami J, Ito H, et al. Clinical features and outcomes of patients with stage I multiple primary lung cancers. Cancer Sci 2020 Nov 25. 
6. Chen TF, Xie CY, Rao BY, Shan SC, Zhang X, Zeng B, Lei YY, Luo HH. Surgical treatment to multiple primary lung cancer patients: a systematic review and meta-analysis. BMC Surg 2019 Dec 03;19(1).

7. lasonos A, Schrag D, Raj GV, Panageas KS. How to build and interpret a nomogram for cancer prognosis. J Clin Oncol 2008 Mar 10;26(8).

8. Callegaro D, Miceli R, Mariani L, Raut CP, Gronchi A. Soft tissue sarcoma nomograms and their incorporation into practice. Cancer 2017 Aug 01;123(15).

9. Caulfield S, Menezes G, Marignol L, Poole C. Nomograms are key decision-making tools in prostate cancer radiation therapy. Urol Oncol 2018 Jun;36(6).

10. Song CK, Guo ZX, Shen XY, Wang YJ, Wang QW, Yu DH, Chen C, Liu XP, Huang JY, Li S, Hu W. Prognostic Factors Analysis and Nomogram Construction of Dual Primary Lung Cancer: A Population Study. Biomed Res Int 2020;2020.

11. Muranishi Y, Sonobe M, Hamaji M, Kawaguchi A, Hijiya K, Motoyama H, Menju T, Aoyama A, ChenYoshikawa TF, Sato T, Date H. Surgery for metachronous second primary lung cancer versus surgery for primary lung cancer: a propensity score-matched comparison of postoperative complications and survival outcomes. Interact Cardiovasc Thorac Surg 201804 01;26(4).

12. Creach KM, Bradley JD, Mahasittiwat P, Robinson CG. Stereotactic body radiation therapy in the treatment of multiple primary lung cancers. Radiother Oncol 2012 Jul;104(1).

13. Nagasaka M, Gadgeel SM. Role of chemotherapy and targeted therapy in early-stage non-small cell lung cancer. Expert Rev Anticancer Ther 2018 01;18(1).

14. Detterbeck FC, Jones DR, Kernstine KH, Naunheim KS, American College of Physicians. Lung cancer. Special treatment issues. Chest 2003 Jan;123.

15. Shan S, She J, Xue ZQ, Su CX, Ren SX, Wu FY. Clinical characteristics and survival of lung cancer patients associated with multiple primary malignancies. PLoS One 2017;12(9).

16. Chen TF, Xie CY, Rao BY, Shan SC, Zhang X, Zeng B, Lei YY, Luo HH. Surgical treatment to multiple primary lung cancer patients: a systematic review and meta-analysis. BMC Surg 2019 Dec 03;19(1);

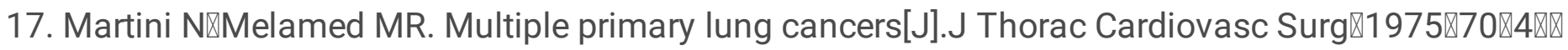
606.

\section{Figures}




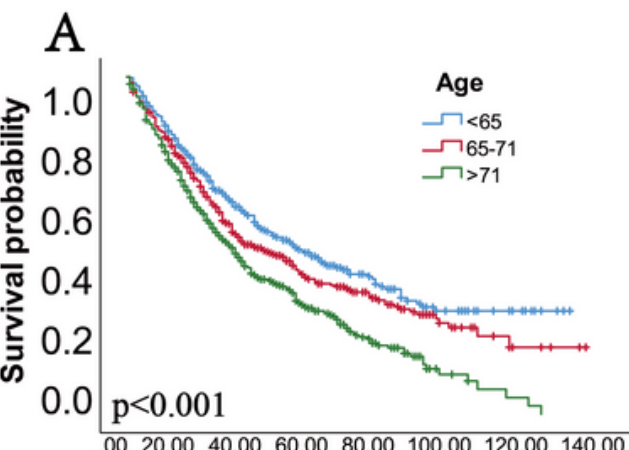

OS Time (Months)

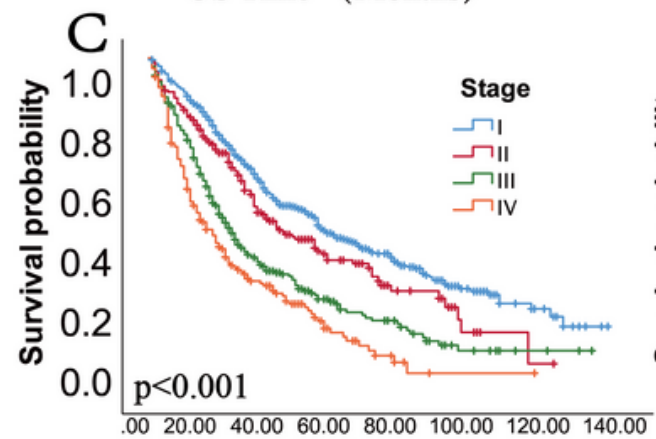

OS Time (Months)

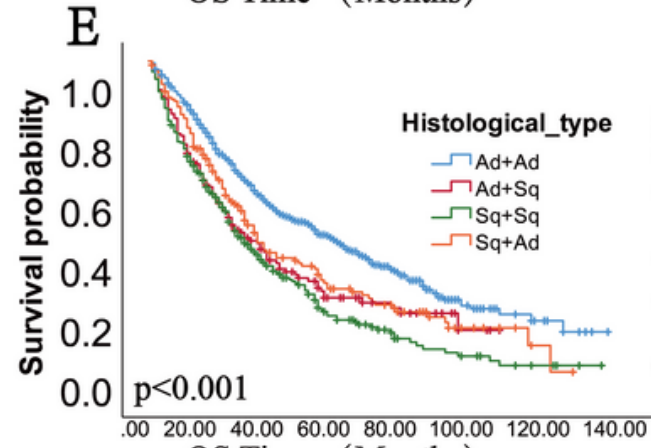

OS Time (Months)

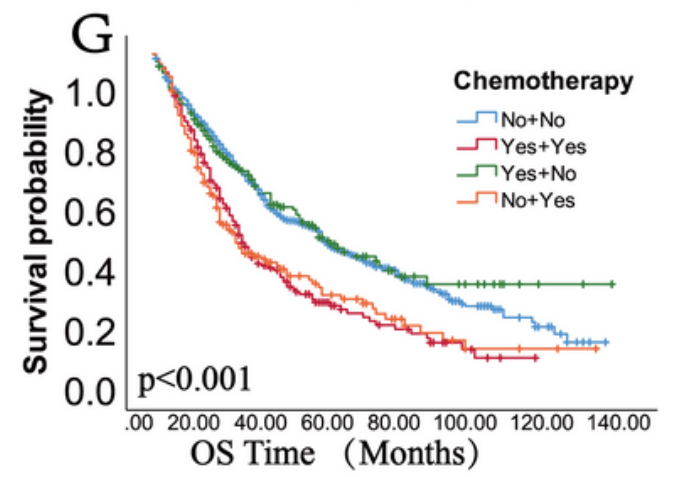

B

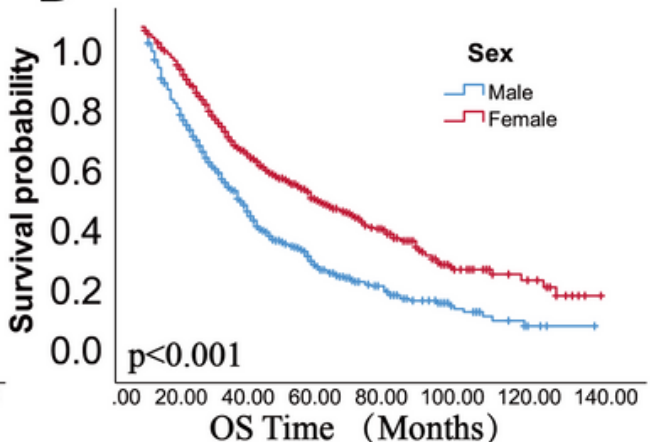

$\mathrm{D}$

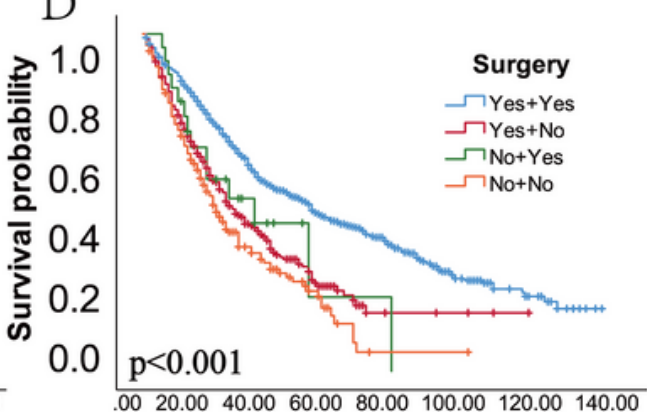

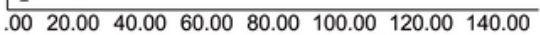

OS Time (Months)

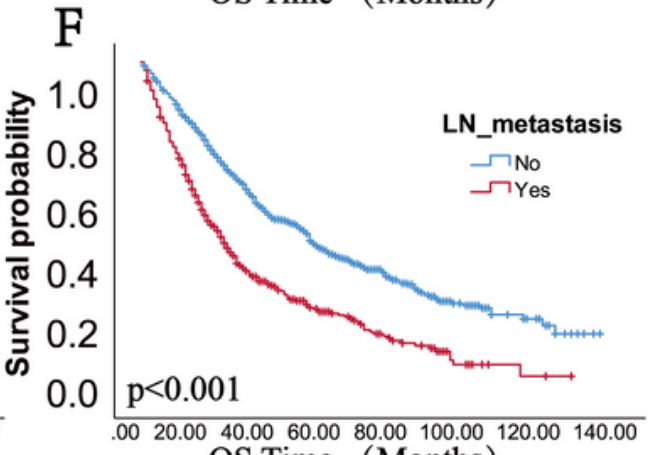

OS Time (Months)

\section{Figure 1}

Kaplan-Meier method of independent prognostic factors on DPLC. 

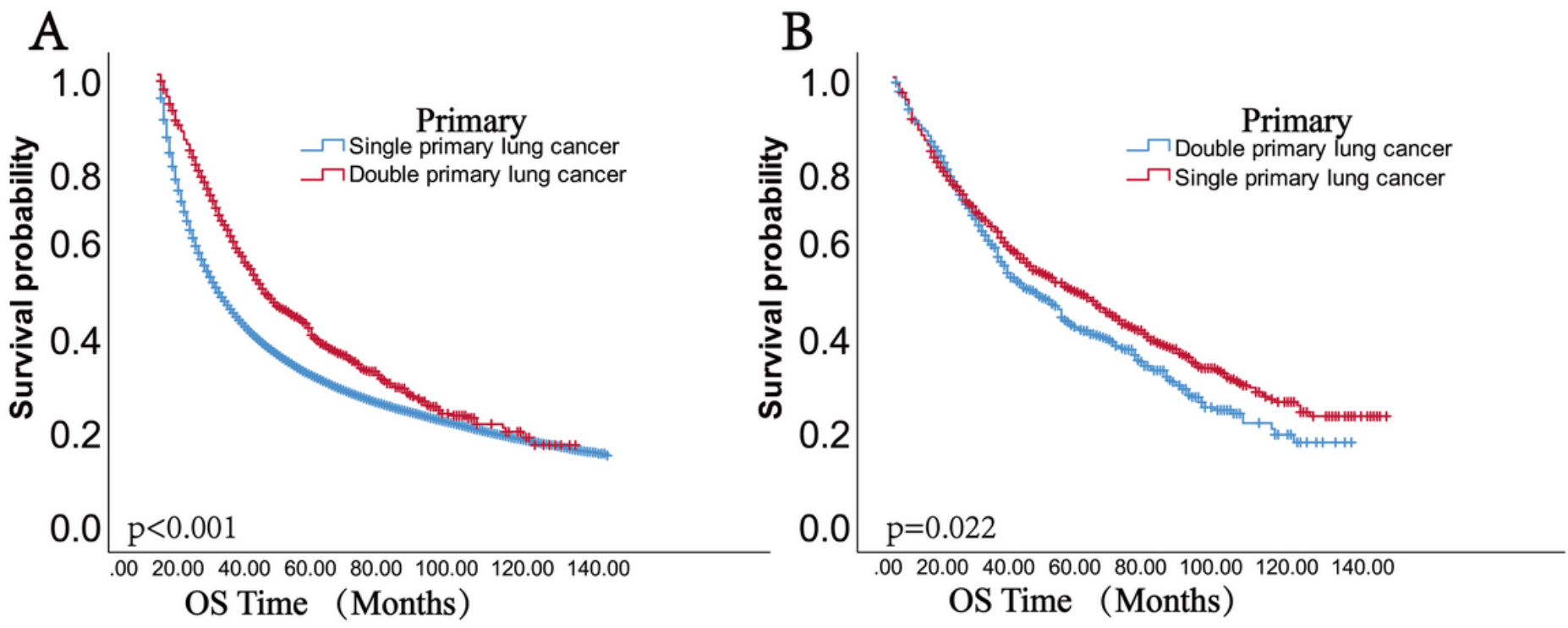

\section{Figure 2}

Kaplan-Meier method of single primary lung cancer and double primary lung cancer. (A) Kaplan-Meier method of single primary lung cancer and double primary lung cancer without PSM $(p<0.001)$. (B) Kaplan-Meier method of single primary lung cancer and double primary lung cancer with PSM $(\mathrm{p}<$ 0.022). 


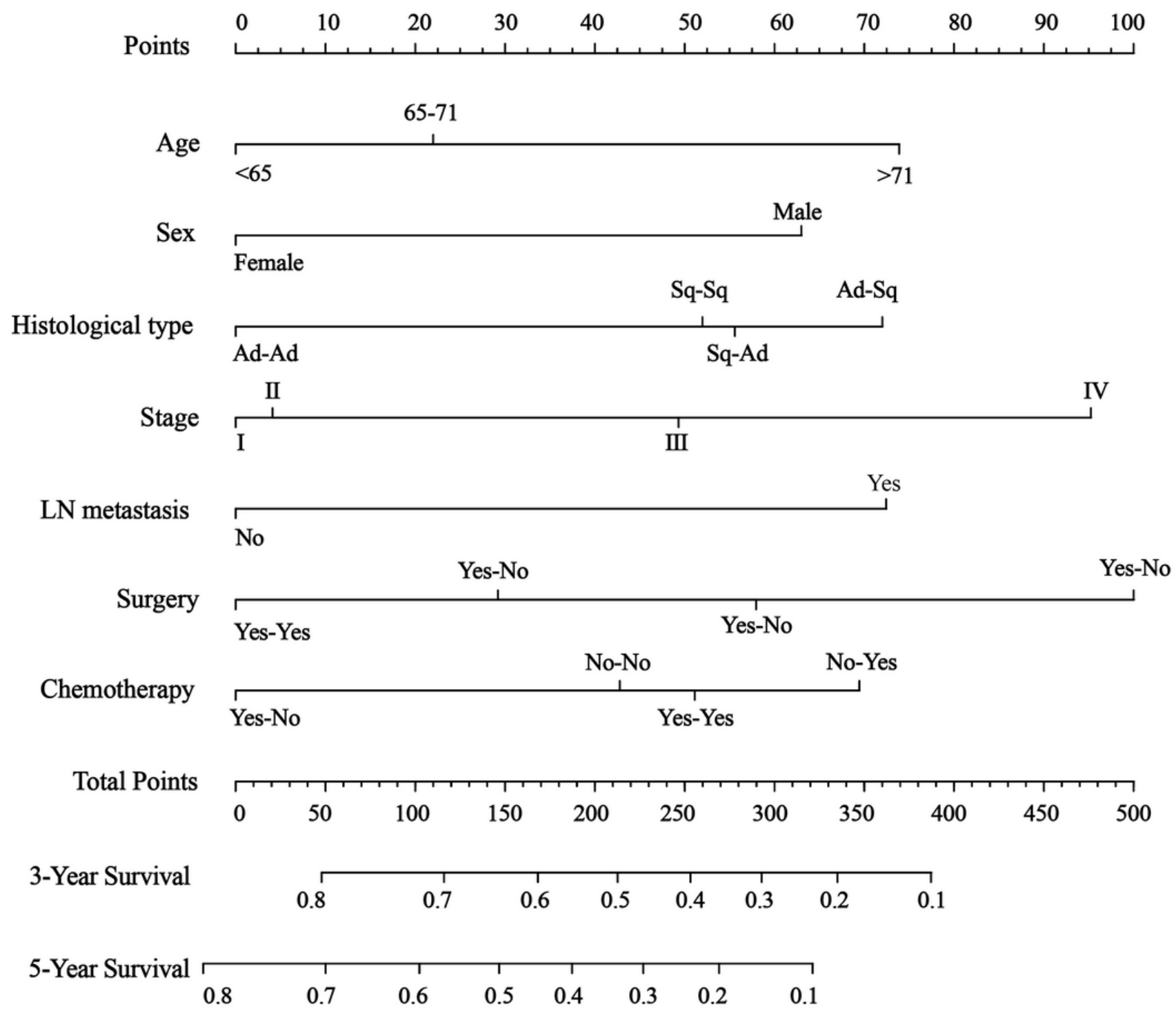

\section{Figure 3}

The nomogram of DPLC. To predict the survival time of DPLC patients, the patients' information of training cohort was used to establish a nomogram including aforementioned significant factors 
A
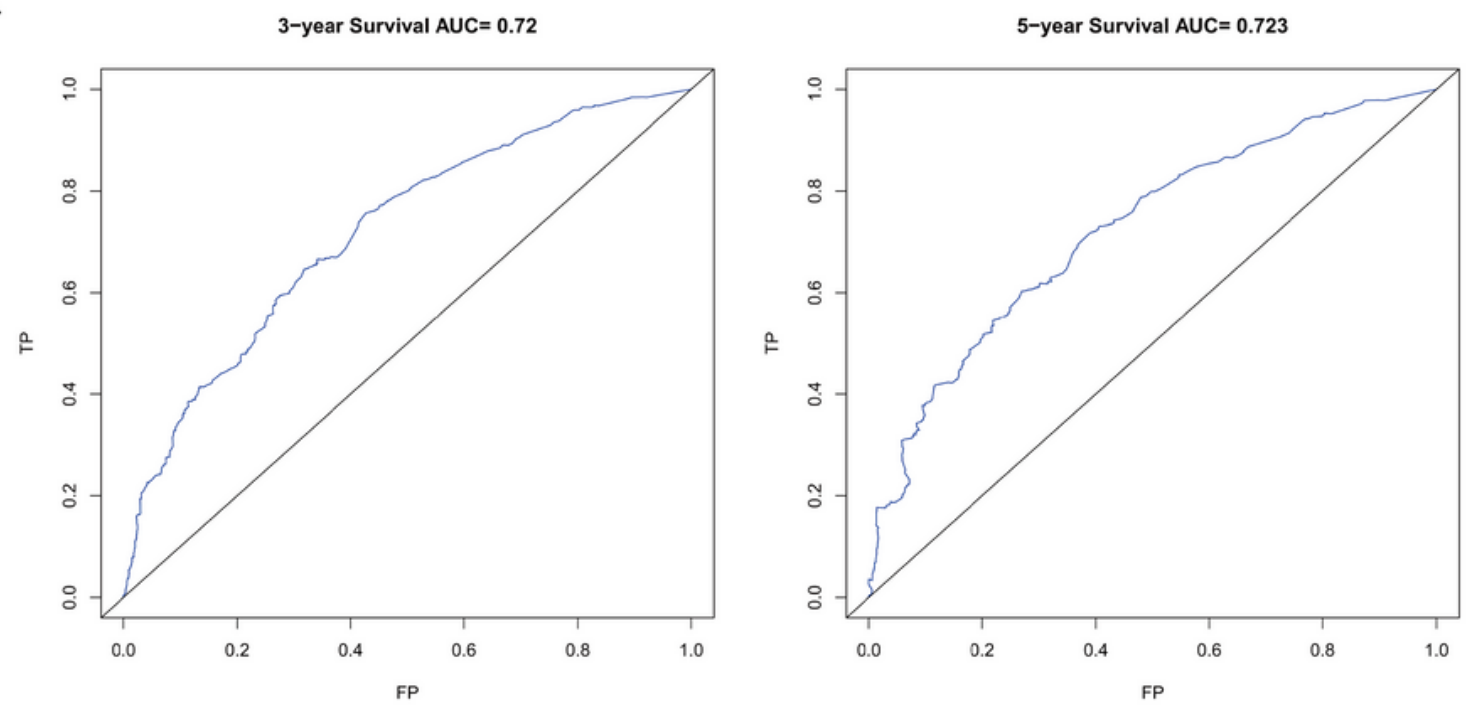

B
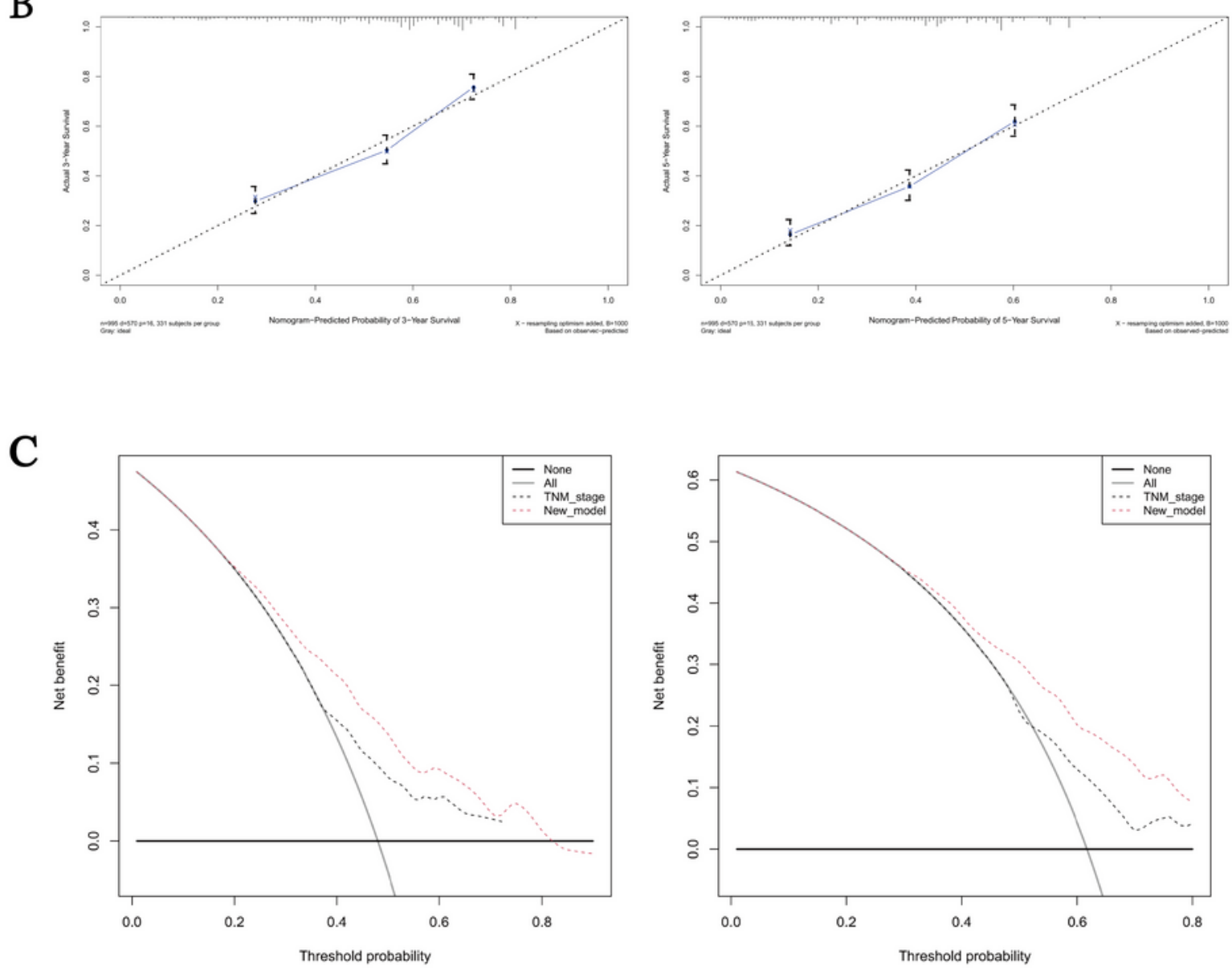

\section{Figure 4}

Validation of predictive model's accuracy. Accuracy of the nomogram was examined by the $\mathrm{C}$ - index, the ROC curve, the calibration chart according to training cohort.

\section{Supplementary Files}


This is a list of supplementary files associated with this preprint. Click to download.

- Figuresupplement1.tif

- Tablesupplement1.doc 